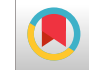

\title{
Association Between Serum Cadmium and Arsenic Levels with Bladder Cancer: A Case-control Study
}

\author{
Vahid Moazed (iD ${ }^{1}$, Elham Jafari (iD ${ }^{2,}{ }^{*}$, Mohammad Reza Ebadzadeh (iD) ${ }^{3}$, Amin Pourzare (iD ${ }^{4}$, Hamid Reza \\ Gharehchahi (iD ${ }^{4}$, Forogh Mangeli (ii) ${ }^{5}$ and Elena Jamali (iD) ${ }^{6}$ \\ ${ }^{1}$ Department of Hematology and Oncology, Faculty of Medicine, Kerman University of Medical Sciences, Kerman, Iran \\ ${ }^{2}$ Pathology Department, Pathology and Stem Cells Research Center, Kerman University of Medical Sciences, Kerman, Iran \\ ${ }^{3}$ Department of Urology, Kerman University of Medical Sciences, Kerman, Iran \\ ${ }^{4}$ Neuroscience Research Center, Institute of Neuropharmacology, Kerman University of Medical Sciences, Kerman, Iran \\ ${ }^{5}$ Department of Pathology, Taleghani Hospital, Shahid Beheshti University of Medical Sciences, Tehran, Iran \\ ${ }^{6}$ Department of Pathology, Loghman Hakim Hospital, Shahid Beheshti University of Medical Sciences, Tehran, Iran \\ "Corresponding author: Pathology Department, Pathology and Stem Cells Research Center, Kerman University of Medical Sciences, Kerman, Iran. Email: ejfarda@yahoo.com
}

Received 2020 June 21; Revised 2021 May 28; Accepted 2021 June 09.

\begin{abstract}
Background: Bladder cancer is the second most common cancer of the genitourinary system and the eighth cause of cancer death. In addition to known risk factors such as smoking and urinary stones, trace elements are also effective in causing bladder cancer and other cancers.

Objectives: This study was conducted to determine the association between bladder cancer and the carcinogens cadmium and arsenic.

Methods: This case-control study was conducted on 40 patients with bladder cancer admitted to Shahid Bahonar Hospital and a control group of 40 healthy individuals in Kerman, Iran, in 2018. The serum levels of arsenic and cadmium were measured by atomic absorptiometry. The paired $t$-test and chi-square tests were employed to assess the difference between cases and controls groups. An unadjusted and 2 multivariable conditional regression models were separately adjusted on sex, family cancer history, residence, occupation, and smoking and were used to estimate odds ratios (OR) and 95\% confidence intervals (95\% CI) to assess the association between arsenic and cadmium levels and bladder cancer. The statistical software SPSS version 26 and R software version 3.6.3 were used to perform the statistical analyses.

Results: The mean cadmium level was $2.99 \pm 1.45$ and $2.59 \pm 0.46$ in the case and control groups, respectively, with no statistically significant difference between the groups $(\mathrm{P}=0.100)$. The mean arsenic level was $2.12 \pm 1.04$ and $1.43 \pm 0.73$ in the case and control groups, respectively, demonstrating a statistically significant difference between the groups $(\mathrm{P}=0.001)$. Unadjusted and adjusted conditional logistic regression models indicated significant association between arsenic levels and bladder cancer (unadjusted: odds ratio (OR) (95\% CI): 0.66 (0.46 - 0.94), P-value = 0.022; adjusted: $\mathrm{OR}(95 \% \mathrm{CI})$ : 0.64 (0.44 - 0.92), P-value $=0.018)$.

Conclusions: Overall, cadmium and arsenic levels are higher in patients with bladder cancer, with a statistically significant difference for arsenic. However, these elements are not interrelated and are not related to other factors.
\end{abstract}

Keywords: Bladder Cancer, Arsenic, Cadmium

\section{Background}

Bladder cancer is globally the fourth and tenth most common cancer among men and women, respectively, with a recurrence rate of $2.3 \%(1,2)$. Urinary tract symptoms, anemia, and weight loss are predominant presentations of bladder cancer $(3,4)$. There are a variety of genetic and environmental risk factors for this cancer $(5,6)$. Reactive oxygen species are among molecular risk factors $(7,8)$, causing DNA alterations and cell damage $(9,10)$. The deficiencies in rare elements such as iron, copper, and zinc are essential causes of malignancies in bladder cancer (1116). Cadmium and arsenic are 2 critical factors that affect the transcription process in gene-related actions, glutathione inhibition, antioxidant defense mechanisms, and the amount of free radicals $(17,18)$.

Cadmium and arsenic can be found in tobacco, and certain foods and are highly distributed in the human body. Their fecal and urinary excretion rate is equal, and both have a long half-life (19-21). Lung, prostate, pancreas, and kidney cancers are associated with cadmium and arsenic (22). Besides, some evidence of their association with uri- 
nary tract cancer has also been reported $(23,24)$.

In Iran, located in southwest Asia, an epidemiological shift from infectious diseases to non-infectious diseases is in progress $(24,25)$. As the third common cause of mortality, cancer poses a serious threat to health in Iran (26). The risk of developing bladder cancer among men and women is on average 3.9:1 (27-29). Due to the burden of disease, the various confirmed and unknown risk factors, the fact that very few studies in the world and virtually no studies in Iran have achieved definitive results in this respect, the social and economic pressures caused by it, and the importance of prevention as the best policy for cancer control, knowledge on the association between carcinogenic factors such as arsenic and cadmium may yield promising results for decreasing the prevalence of cancer in the country.

\section{Objectives}

Given the importance of this issue, this study was conducted to investigate the association between cadmium and arsenic levels and bladder cancer.

\section{Methods}

This case-control study with a control group was conducted by convenience non-random sampling method on 40 patients with bladder cancer diagnoses admitted to the urology department of Shahid Bahonar Hospital in Kerman, Iran, and 40 healthy individuals as the control group, starting from April 2018, for one year.

The researcher explained the objectives and the study method, and those who provided informed consent were included, and those who did not, were excluded. The control group matched the study group in terms of age, sex, and place of residence. The data were gathered using a checklist of demographic information such as age, gender, smoking, and opium use. Then, a blood sample was collected without using anticoagulants, and the arsenic and cadmium levels were measured using atomic absorptiometry. The dilution fluid Triton X-100 0.2\% and Antiform-B $0.2 \%$ solution were added to blood samples; the samples were mixed for 30 seconds and then centrifuged.

The samples were then stored at $-80^{\circ} \mathrm{C}$ in an ice bag until the test procedure. The standards had dilutions of 0 , $0.1,0.5$, and $1 \mu \mathrm{g} / \mathrm{L}$ for cadmium and $0,2,5$, and $10 \mu \mathrm{g} / \mathrm{L}$ for arsenic. The injection of samples and standards to the main container was carried out directly using Hamilton syringes up to $10 \mu \mathrm{L}$. This study was assessed and approved by the Ethics Committee of the Kerman University of Medical Science under ethics codes IR.KMU.REC.1395.954 and IR.KMU.REC.1395.952.

Continuous variables were presented as mean and standard deviation (SD). Based on the results of the Shapiro-Wilk test for normality, a two-sample independent t-test for continuous variables was employed for comparison between case and control groups. The chi-square test was also used for the categorical variables for comparisons between groups. The conditional logistic regression (CLR) model was used to estimate odds ratios (RR), and a 95\% confidence interval ( $95 \% \mathrm{CI}$ ) was calculated for the association between arsenic and cadmium levels and bladder cancer. Associations were first assessed through a univariable model and then using 2 multivariable models. Model 1 was adjusted for the arsenic levels, and potential confounders including sex, family cancer history, residence, occupation, and smoking; model 2 was adjusted for the cadmium levels and the same potential confounders as those of model 1 . All statistical analyses were conducted using SPSS version 26 and R software version 3.6.3; P-value < 0.05 was considered statistically significant.

\section{Results}

A total of 40 patients and 40 healthy individuals were enrolled in this study. The mean age of participants in the case and control groups was $60.2 \pm 14.2$ and $59.6 \pm 13.4$, respectively. In the case and control groups there were 32 and 29 males, respectively. The 2 groups were matched regarding their family history, occupation, living place, opium use, and smoking $(\mathrm{P}>0.05)$. The mean cadmium level in the case and control groups was $2.99 \pm 1.45$ and $2.59 \pm 0.46$ ( $\mathrm{ng} / \mathrm{mL})$, respectively with no statistically significant difference between the groups $(\mathrm{P}=0.100)$. The reference value for the cadmium level was $0.5-2.0 \mathrm{ng} / \mathrm{mL}$ (30). Cadmium levels were associated with none of the variables in either group or with the pathological grade of bladder cancer according to the World Health Organization (WHO) classification $(\mathrm{P}>0.05)$ (Table 1$)$.

\begin{tabular}{lcc}
\hline $\begin{array}{l}\text { Table 1. Serum Levels of Cadmium in Patients and Pathological Grade of Bladder } \\
\text { Cancer }\end{array}$ & Mean \pm SD & P-Value \\
\hline Pathology & $2.71 \pm 1.37$ & 0.325 \\
\hline Low grade & $2.86 \pm 1.51$ & 0.231 \\
\hline High grade &
\end{tabular}

The mean arsenic level was $2.12 \pm 1.04$ and $1.43 \pm 0.73$ in the case and control groups, respectively, with a statistically significant difference between the groups $(\mathrm{P}=0.001)$. 
The reference value for serum arsenic levels was $9.87 \mu \mathrm{g} / \mathrm{L}$ (30). Unlike cadmium, arsenic levels had a statistically significant difference with the pathological grade $(\mathrm{P}<0.05)$ (Table 2). There was no significant correlation between arsenic and cadmium levels ( $\mathrm{P}>0.05)$.

\begin{tabular}{|c|c|c|}
\hline Pathology & Mean \pm SD & P-Value \\
\hline Low grade & $1.02 \pm 0.134$ & 0.045 \\
\hline High grade & $1.23 \pm 0.256$ & 0.031 \\
\hline
\end{tabular}

As is shown in Table 3, we did not observe any significant association between cadmium level and bladder cancer in unadjusted and adjusted models ( $\mathrm{P}>0.05$ ). However, a significant association was found in both the univariate CLR model (OR (95\%CI): 0.66 (0.46 - 0.94), P-value = 0.022) or multivariate CLR model (OR (95\%CI): 0.64 (0.44 $0.92)$, P-value $=0.018$ ) between arsenic levels and bladder cancer (Table 3).

\section{Discussion}

Dealing with cadmium and arsenic levels is among the most significant concerns in public health, primarily due to their confirmed carcinogenicity. Numerous epidemiologic, toxicologic, pharmacologic, and laboratory studies have focused on the dose-response of arsenic and cadmium on cancer and other health-related issues $(23,31-33)$. A recent study has shown that, according to evidence, there is a dose-response relationship between arsenic and cadmium and cancer, in which non-toxic processes progress towards oncogenesis when exposed to the adequate dose of arsenic and cadmium for the proper length of time (34).

The water and soil levels of arsenic in Kerman province have been reported to be $0.12 \mathrm{mg} / \mathrm{kg}$ and $0.0 \mathrm{mg} / \mathrm{kg}$, respectively, which are within the standard range (lower than 4.5 $\mathrm{g} / \mathrm{kg}$ ) in soil but is higher than the permissible level ( 0.01 $\mathrm{mg} / \mathrm{L}$ ) in water (35). Abbaszadeh et al. (36) showed higher water arsenic levels in the southern and western parts of Kerman Province, not only because of industry and agriculture in this region but most likely due to geogenic origins. The cadmium exposure rate was $6 \mu \mathrm{g} / \mathrm{L}$ in water and 5 - 25 $\mathrm{mg} / \mathrm{kg}$ in soil. The world standards for cadmium are 1 - 3 $\mu \mathrm{g} / \mathrm{L}$ for water and $0.2-11 \mathrm{mg} / \mathrm{kg}$ for soil (26). Although it has been shown that low-level exposure to cadmium has no irreversible effect on the urinary tract (27), long-term, high-level exposure affects bone density (28), and results in a higher risk of developing lung cancer (22) and DNA alteration in urothelial cells (29). The cadmium level was similar in the 2 groups and was not related to other variables.
The study carried out by Kellen et al. (23) showed higher cadmium levels in patients with bladder cancer. However, we found no significant difference in cadmium levels between the 2 groups, which may be due to the small sample size and different measurement methods in the 2 studies. Feki-Tounsi et al. (31) reported significantly higher cadmium levels associated with smoking in patients with bladder cancer. However, in our study, smoking had no significant effect on cadmium levels. Inconsistency in results despite similar methods may be due to the small sample size of our study. Feki-Tounsi and Hamza-Chaffai (32) also argued in a review article that cadmium is toxic to urothelial cells and acts as a carcinogenic agent.

Sens et al. (24) demonstrated that in vitro exposure of urothelial cells to cadmium and arsenic results in malignant transformation. Talaat et al. (25) also reported a higher expression rate of the kindlin-2 gene in exposure to arsenic and cadmium. A higher tissue level of cadmium in patients with bladder cancer was also reported by AbdelGawad et al. (34). Nawrot et al. (22) reported the significant effect of high exposure to cadmium on bladder cancer development in a cohort study.

In contrast to previous studies, which measured the water and soil levels of arsenic, we measured the serum level as a marker of chronic exposure. We found a significant association between arsenic and bladder cancer with unadjusted and adjusted conditional logistic regression models. Feki-Tounsi et al. (31) reported similar results as they observed 3 fold amounts of arsenic in the case group compared to the controls. Similarly, in their study, the stage and grade were not associated with arsenic levels. They reported that occupation and smoking are associated with arsenic levels, which is not in agreement with our study. The inconsistency in results may be due to the smaller sample size in our study. The role of kindlin-2 was again reported to be related to the effect of both arsenic and cadmium (25). In Sens et al.'s study, immunodeficient mice were assessed using 3 methods: real-time polymerase chain reaction, Western analysis, and immunohistochemistry assessment for the kindlin-2 gene demonstrating an increase in the risk of developing cancer in the case group (24).

\subsection{Conclusions}

Overall, our study shows cadmium and arsenic levels are higher in patients with bladder cancer, with a statistically significant difference in the case of arsenic. However, these elements are not interrelated and are not related to other factors such as gender, smoking, opium use, and living in urban areas. Further studies with a large sample are recommended to achieve better results. 


\begin{tabular}{|c|c|c|c|c|c|c|}
\hline \multirow{2}{*}{ Variables } & \multicolumn{2}{|c|}{ Unadjusted } & \multicolumn{2}{|c|}{ Adjusted (Model $1^{\mathrm{b}}$ ) } & \multicolumn{2}{|c|}{ Adjusted (Model $2^{b}$ ) } \\
\hline & $\mathrm{OR}(95 \% \mathrm{CI})$ & P-Value & OR $(95 \% \mathrm{CI})$ & P-Value & $\mathrm{OR}(95 \% \mathrm{CI})$ & P-Value \\
\hline Arsenic levels, $\mathrm{ng} / \mathrm{mL}$ & $0.66(0.46-0.94)$ & 0.022 & - & - & $0.64(0.44,0.92)$ & 0.018 \\
\hline Cadmium levels, ng/mL & $1.13(0.92-1.38)$ & 0.242 & $1.17(0.95-1.45)$ & 0.134 & - & - \\
\hline Sex (female) & $0.80(0.37-1.74)$ & 0.578 & $0.83(0.38-1.81)$ & 0.634 & $0.63(0.28-1.41)$ & 0.259 \\
\hline Family cancer history (no) & $0.75(0.33-1.70)$ & 0.492 & $0.60(0.25-1.48)$ & 0.271 & $0.78(0.33-1.86)$ & 0.573 \\
\hline Residence & $1.17(0.62-2.21)$ & 0.622 & $1.23(0.64-2.35)$ & 0.54 & $1.09(0.58-2.06)$ & 0.795 \\
\hline Occupation & $1.02(0.85-1.22)$ & 0.856 & $1.05(0.86-1.27)$ & 0.642 & $1.06(0.88-1.27)$ & 0.536 \\
\hline Smoking (yes) & $1.16(0.62-2.16)$ & 0.635 & $1.37(0.70-2.68)$ & 0.362 & $1.11(0.58-2.14)$ & 0.746 \\
\hline
\end{tabular}

Abbreviations: OR, odds ratios and 95\% confidence intervals (OR [95\% CI]) for estimation using conditional logistic regression.

${ }^{a}$ Note: arsenic levels and cadmium levels were used as continuous variables in conditional logistic regression models.

${ }^{\mathrm{b}}$ Model 1, adjusted on arsenic levels, sex, family cancer history, residence, occupation, and smoking; model 2, adjusted on cadmium levels, sex, family cancer history, residence, occupation, and smoking.

\section{Footnotes}

Authors' Contribution: Study concept and design: Vahid Moazed and Elham Jafari. Acquisition of data: Mohammad Reza Ebadzadeh and Hamid Reza Gharehchahi. Analysis and interpretation of data: Elham Jafari, Amin Pourzare, and Hamid Reza Gharehchahi. Drafting of the manuscript: Elham Jafari and Forogh Mangeli. Critical revision of the manuscript for important intellectual content: Forogh Mangeli and Elena Jamali. Statistical analysis: Amin Pourzare, Hamid Reza Gharehchahi, and Forogh Mangeli. Administrative, technical, and material support: Elham Jafari. Study supervision: Vahid Moazed.

Conflict of Interests: The authors declare no conflict of interest.

Ethical Approval: This study was assessed and approved by the Ethics Committee of the Kerman University of Medical Science under ethics codes IR.KMU.REC.1395.954 and IR.KMU.REC.1395.952.

Funding/Support: This work was financially supported by the Pathology and Stem Cell Research Center, associated with the University of Medical Sciences, Kerman, Iran (grant numbers: 95/662 and 95/663).

\section{References}

1. Siegel R, Ma J, Zou Z, Jemal A. Cancer statistics, 2014. CA Cancer J Clin. 2014;64(1):9-29. doi: 10.3322/caac.21208. [PubMed: 24399786].

2. Shah JB, McKiernan JM. Novel therapeutics in the treatment of bladder cancer. Curr Opin Urol. 2004;14(5):287-93. doi: 10.1097/00042307200409000-00007. [PubMed: 15300149].

3. Zhou J, Kelsey KT, Smith S, Giovannucci E, Michaud DS. Lower Urinary Tract Symptoms and Risk of Bladder Cancer in Men: Results From the Health Professionals Follow-up Study. Urology. 2015;85(6):1312-8. doi: 10.1016/j.urology.2015.02.024. [PubMed: 25863833]. [PubMed Central: PMC4479979].
4. Clark PE, Agarwal N, Biagioli MC, Eisenberger MA, Greenberg RE, Herr HW, et al. Bladder cancer. J Natl Compr Canc Netw. 2013;11(4):446-75. doi: 10.6004/jnccn.2013.0059. [PubMed: 23584347].

5. Letasiova S, Medve'ova A, Sovcikova A, Dusinska M, Volkovova K, Mosoiu C, et al. Bladder cancer, a review of the environmental risk factors. Environ Health. 2012;11 Suppl 1. S11. doi: 10.1186/1476-069X-11-S1-S11. [PubMed: 22759493]. [PubMed Central: PMC3388449].

6. Burger M, Catto JW, Dalbagni G, Grossman HB, Herr H, Karakiewicz $\mathrm{P}$, et al. Epidemiology and risk factors of urothelial bladder cancer. Eur Urol.2013;63(2):234-41. doi:10.1016/j.eururo.2012.07.033. [PubMed: 22877502].

7. Akcay T, Saygili I, Andican G, Yalcin V. Increased formation of 8hydroxy-2'-deoxyguanosine in peripheral blood leukocytes in bladder cancer. Urol Int. 2003;71(3):271-4. doi: 10.1159/000072677. [PubMed: 14512647].

8. Knight JA. Free radicals: their history and current status in aging and disease. Ann Clin Lab Sci. 1998;28(6):331-46. [PubMed: 9846200].

9. Toyokuni S. Reactive oxygen species-induced molecular damage and its application in pathology. Pathol Int. 1999;49(2):91-102. doi: 10.1046/j.1440-1827.1999.00829.x. [PubMed:10355961].

10. Pryor W. Free radicals in biology. Elsevier; 2012.

11. Valko M, Rhodes CJ, Moncol J, Izakovic M, Mazur M. Free radicals, metals and antioxidants in oxidative stress-induced cancer. Chem Biol Interact. 2006;160(1):1-40.doi:10.1016/j.cbi.2005.12.009. [PubMed: 16430879].

12. Shazia Q, Mohammad ZH, Rahman T, Shekhar HU. Correlation of oxidative stress with serum trace element levels and antioxidant enzyme status in Beta thalassemia major patients: a review of the literature. Anemia.2012;2012:270923. doi: 10.1155/2012/270923. [PubMed: 22645668]. [PubMed Central: PMC3357501].

13. Barrera-Garcia A, O'Hara T, Galvan-Magana F, Mendez-Rodriguez LC, Castellini JM, Zenteno-Savin T. Trace elements and oxidative stress indicators in the liver and kidney of the blue shark (Prionace glauca). Comp Biochem Physiol A Mol Integr Physiol. 2013;165(4):483-90. doi: 10.1016/j.cbpa.2013.01.024. [PubMed: 23388211].

14. Sosa V, Moline T, Somoza R, Paciucci R, Kondoh H, L. Leonart ME. Oxidative stress and cancer: an overview. Ageing Res Rev. 2013;12(1):376-90. doi: 10.1016/j.arr.2012.10.004. [PubMed: 23123177].

15. Prasad AS. Essential and toxic element: trace elements in human health and disease. Elsevier; 2013.

16. Mazdak H, Yazdekhasti F, Movahedian A, Mirkheshti N, Shafieian M. The comparative study of serum iron, copper, and zinc levels between bladder cancer patients and a control group. Int Urol Nephrol. 2010;42(1):89-93. doi: 10.1007/s11255-009-9583-4. [PubMed: 19548109]. 
17. Goyer RA, Liu J, Waalkes MP. Cadmium and cancer of prostate and testis. Biometals. 2004;17(5):555-8. doi: 10.1023/b:biom.0000045738.59708.20. [PubMed: 15688863].

18. Hartwig A. Cadmium and cancer. Met Ions Life Sci. 2013;11:491-507. doi: 10.1007/978-94-007-5179-8_15. [PubMed: 23430782].

19. Kirkham MB. Cadmium in plants on polluted soils: Effects of soil factors, hyperaccumulation, and amendments. Geoderma. 2006;137(12):19-32. doi: 10.1016/j.geoderma.2006.08.024.

20. Satarug S, Garrett SH, Sens MA, Sens DA. Cadmium, environmental exposure, and health outcomes. Cien Saude Colet. 2011;16(5):2587-602 doi: 10.1590/s1413-81232011000500029. [PubMed: 21655733]. [PubMed Central: PMC5967636].

21. Godt J, Scheidig F, Grosse-Siestrup C, Esche V, Brandenburg P, Reich $\mathrm{A}$, et al. The toxicity of cadmium and resulting hazards for human health. J Occup Med Toxicol. 2006;1:22. doi: 10.1186/1745-6673-1-22. [PubMed:16961932]. [PubMed Central: PMC1578573].

22. Nawrot T, Plusquin M, Hogervorst J, Roels HA, Celis H, Thijs L, et al. Environmental exposure to cadmium and risk of cancer: prospective population-based study. Lancet Oncol. 2006;7(2):119-26. doi: 10.1016/S1470-2045(06)70545-9. [PubMed: 16455475].

23. Kellen E, Zeegers MP, Hond ED, Buntinx F. Blood cadmium may be associated with bladder carcinogenesis: the Belgian case-control study on bladder cancer. Cancer Detect Prev. 2007;31(1):77-82. doi: 10.1016/j.cdp.2006.12.001. [PubMed: 17296271].

24. Sens DA, Park S, Gurel V, Sens MA, Garrett SH, Somji S. Inorganic cadmium- and arsenite-induced malignant transformation of human bladder urothelial cells. Toxicol Sci. 2004;79(1):56-63. doi: 10.1093/toxsci/kfh086. [PubMed: 14976345].

25. Talaat S, Somji S, Toni C, Garrett SH, Zhou XD, Sens MA, et al. Kindlin2 expression in arsenite- and cadmium-transformed bladder cancer cell lines and in archival specimens of human bladder cancer. Urology. 2011;77(6):1507 e1-7. doi: 10.1016/j.urology.2011.02.040. [PubMed 21624607]. [PubMed Central: PMC3105253].

26. Vodyanitskii YN. Standards for the contents of heavy metals in soils of some states. Ann Agrarian Sci. 2016;14(3):257-63. doi 10.1016/j.aasci.2016.08.011.

27. Hotz P, Buchet JP, Bernard A, Lison D, Lauwerys R. Renal effects of lowlevel environmental cadmium exposure: 5-year follow-up of a sub- cohort from the Cadmibel study. Lancet. 1999;354(9189):1508-13. doi: 10.1016/s0140-6736(99)91145-5. [PubMed:10551497].

28. Staessen JA, Kuznetsova T, Roels HA, Emelianov D, Fagard R. Exposure to cadmium and conventional and ambulatory blood pressures in a prospective population study. Public Health and Environmental Exposure to Cadmium Study Group. Am J Hypertens. 2000;13(2):146-56. doi: 10.1016/s0895-7061(99)00187-9. [PubMed: 10701814].

29. Filipic M, Fatur T, Vudrag M. Molecular mechanisms of cadmium induced mutagenicity. Hum Exp Toxicol. 2006;25(2):67-77. doi: 10.1191/0960327106ht590oa. [PubMed: 16539211].

30. Freire C, Koifman RJ, Fujimoto D, de Oliveira Souza VC, Barbosa FJ, Koifman S. Reference values of cadmium, arsenic and manganese in blood and factors associated with exposure levels among adult population of Rio Branco, Acre, Brazil. Chemosphere. 2015;128:70-8. doi: 10.1016/j.chemosphere.2014.12.083. [PubMed: 25655821].

31. Feki-Tounsi M, Olmedo P, Gil F, Khlifi R, Mhiri MN, Rebai A, et al. Cadmium in blood of Tunisian men and risk of bladder cancer: interactions with arsenic exposure and smoking. Environ Sci Pollut Res Int. 2013;20(10):7204-13. doi: 10.1007/s11356-013-1716-8. [PubMed: 23673919].

32. Feki-Tounsi M, Hamza-Chaffai A. Cadmium as a possible cause of bladder cancer: a review of accumulated evidence. Environ Sci Pollut Res Int. 2014;21(18):10561-73. doi: 10.1007/s11356-014-2970-0. [PubMed: 24894749].

33. Gecit I, Kavak S, Demir H, Gunes M, Pirincci N, Cetin C, et al. Serum trace element levels in patients with bladder cancer. Asian PacJCancer Prev. 2011;12(12):3409-13. [PubMed: 22471489].

34. Abdel-Gawad M, Elsobky E, Shalaby MM, Abd-Elhameed M, AbdelRahim M, Ali-El-Dein B. Quantitative Evaluation of Heavy Metals and Trace Elements in the Urinary Bladder: Comparison Between Cancerous, Adjacent Non-cancerous and Normal Cadaveric Tissue. Biol Trace Elem Res. 2016;174(2):280-6. doi: 10.1007/s12011-016-0724-1. [PubMed: 27147435].

35. Guidelines for drinking-water quality: Fourth edition incorporating the first addendum. 2017.

36. Abbaszadeh M. Modelling Spatial Variation of Arsenic Pollutant Using Empirical Bayesian Kriging in the Southern Part of Kerman Province. Iran South Med J. 2018;20(6):584-94. 